\title{
The fourth International conference on Recent Advances and Controversies in Measuring Energy Metabolism (RACMEM)
}

\author{
Abdul G Dulloo ${ }^{1} \cdot$ Jennifer L Miles-Chan ${ }^{1} \cdot$ Yves Schutz $^{1}$ \\ Received: 7 February 2018 / Accepted: 10 February 2018 \\ (c) Macmillan Publishers Limited, part of Springer Nature 2018
}

Major advances in science rarely follow smooth trajectories. Rather, they are propelled by milestone events that are often the outcome of the development of new tools, improved measuring systems, novel ways of data processing, the resolution of controversies, or the birth of novel concepts. It is in this spirit that the triennial international conference focusing on Recent Advances and Controversies in Measuring Energy Metabolism (RACMEM) provides a forum for scientists from both academia and industry to meet and discuss the latest advances, controversies, and methodological issues related to the assessment of energy expenditure and substrate oxidation in humans and animals.

Like past RACMEM events held in Colorado (2008), Maastricht (2011), and Tokyo (2014), this latest RACMEM event held in Fribourg in 2017, and attended by 184 young and older scientists from across the world (Europe, Asia, America, and Australasia), accomplished the specific learning objectives: (i) to review the latest approaches in measuring energy expenditure and fuel utilization in-vivo and establish basic standards for preclinical and clinical research, (ii) to address the current controversies in the expression and interpretation of metabolic data, and (iii) to assess the methodological and technological gaps in our pursuit to understand in-vivo fuel metabolism in order to direct research and development efforts.

This was achieved through a two-day packed program, consisting of (i) keynote lectures (published in this issue of EJCN), (ii) symposium sessions involving a total of 20 experts that addressed the design of calorimeter systems, the expression and analysis of metabolic data, advances in free-living assessments, and the implementation and monitoring of

Abdul G Dulloo

abdul.dulloo@unifr.ch

1 Department of Endocrinology, Metabolism and Cardiovascular System, Faculty of Sciences and Medicine, University of Fribourg, Fribourg, Switzerland physical activity in humans and animals, (iii) freecommunication sessions, which provided a venue for 20 short oral communications (mostly by young scientists) and 66 poster presentations by conference attendees, (iv) points of view and debate about controversial topics on the definitions of 'Metabolic Flexibility' and whether switching brown adipose tissue to cure obesity will work or not, and (iv) exhibitions showing and presenting established and new products that can be used for human and animal metabolic research.

A novelty in this fourth RACMEM event in Fribourg, which the International Organizing Committee intends to continue in future events, is to pay tribute to past or retired outstanding scientists in our field through 'The RACMEM Lecture'. For this 2017 event, we paid tribute to the late John Garrow (1929-2016) who imprinted our field with his research work embodied in his two famous books: "Energy Balance \& Obesity" and "Treat Obesity Seriously".

RACMEM 2017 was also enriched by two half-day premeeting satellite symposia: one focused on the 'Recent advances \& current issues in the use of the doubly-labeled water technique', and the other centered upon 'Novel concepts in the relationships between body composition, energy balance regulation \& cardiometabolic health'. The proceedings of the latter symposium are constituted by 6 review papers published in this issue of EJCN. We are grateful to the authors of the symposium reviews, as well as to our keynote lecturers for their contributions to this EJCN issue.

Last but not least, we would like to thank the RACMEM International Organizing Committee for giving us the opportunity and their invaluable help in organizing this event at our university campus in Fribourg. We are all looking forward to meet again and share our experiences and friendships at the next RACMEM event in Canada in 2020 .

\section{Compliance with ethical standards}

Conflict of interest The authors declare that they have no conflict of interest. 